\title{
LETTERS
}

\section{Necrotising myositis in Behçet's disease: characteristic features on magnetic resonance imaging and a review of the literature}

\author{
H Sarui, T Maruyama, I Ito, N Yamakita, N Takeda, M Nose, K Yasuda
}

Ann Rheum Dis 2002;61:751-752

M yositis is rarely associated with Behçet's disease. We report such a case with characteristic magnetic resonance imaging (MRI) findings, and review the literature.

\section{CASE REPORT}

A 29 year old man was first admitted to Matsunami General Hospital because of high fever and muscle pain of both lower legs, finally resulting in him being unable to walk. Painful multiple subcutaneous nodules of both lower legs and the left arm were seen. There was no history of trauma. Total leucocytes, erythrocyte sedimentation rate, and $\mathrm{C}$ reactive protein were raised. The serum creatine kinase value was normal. An MRI study of the lower legs (fig 1) showed a focal mass-like lesion, about $3 \mathrm{~cm}$ in diameter, in the left gastrocnemius muscle with a decreased intensity on a $T_{1}$ weighted image compared with that for normal muscle. Gadolinium enhanced $T_{1}$ weighted images showed a well defined rim of contrast enhancement and a hypointense central area. An axial $\mathrm{T}_{2}$ weighted image showed bright signal intensity in and around the focal mass-like lesion. The same MRI findings were seen in the other nodules of the lower legs. Computed tomography (CT) did not disclose the focal mass-like lesion. Antibiotics were not effective. The symptoms and multiple nodules resolved spontaneously about one month after admission, and the patient was discharged.

One month after discharge, he was admitted to our hospital because of a relapse, with similar symptoms. Painful multiple subcutaneous nodules of both lower legs, in different areas from those of his previous admission, were found. MRI findings of the mass lesions were similar to those of the previous admission.

On admission the patient had polyarthritis and skin lesions. Recurrent aphthous ulcerations had been noted over the previous two years. Pathergy testing was positive. A skin biopsy was performed and showed thrombophlebitis. HLA-B51 was positive. From these results, Behçet's disease was diagnosed. A biopsy of a nodule from the left gastrocnemius muscle was carried out. Examination of the muscle biopsy specimen obtained from the nodular lesion showed an inflammatory granulation predominantly with an infiltration of neutrophils and macrophages, associated with focal central necrosis of the muscle and perivasculitis in the surrounding muscular tissue. A culture of the tissue specimen was negative for bacteria. These findings were consistent with necrotising myositis.

The symptoms and multiple nodules of the legs resolved spontaneously. After discharge, colchicine was given, and no painful multiple subcutaneous nodules have reappeared.

\section{DISCUSSION}

We reviewed nine cases of Behçet's disease with myositis reported in English $^{1-9}$ and the present case (table 1). Three were generalised and seven were localised myositis. Painful multiple nodules were not described in the cases. All of the localised cases involved the legs. In our case the histological findings were similar to most of the other reported localised cases; it seems possible that vasculitis as a component of Behçet's disease may participate in the pathogenesis of myositis.

MRI has proved to be better than CT scans for the detection of soft tissue diseases-notably, muscle disorders, but was not described in the cases reviewed above. In diabetic muscle infarction and pyomyositis, a gadolinium infusion showed a slightly enhanced rim and a dark central area in $\mathrm{T}_{1}$ weighted images. Our case suggests that radiological differentiation among these lesions is difficult. A prompt biopsy and a cell culture should be carried out.

Colchicine may be useful for treating genital ulcers, erythema nodosum, and arthritis of Behçet's disease, especially in women. ${ }^{10}$ In the cases reviewed here, only one patient
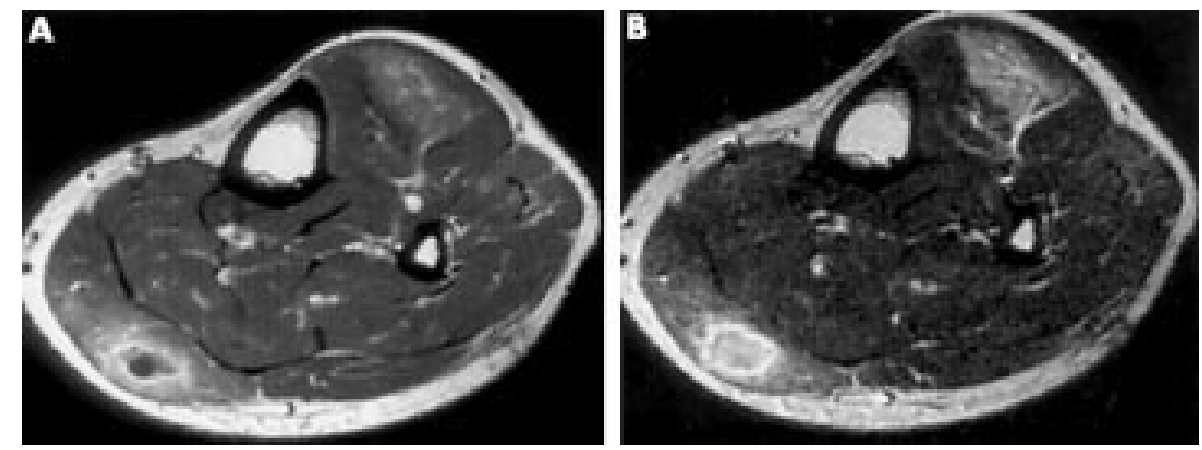

Figure $1 \mathrm{MRI}$ of the lower legs was performed on the patient's first admission. An axial $\mathrm{T}_{1}$ weighted image showed a focal mass-like lesion, about $3 \mathrm{~cm}$ in diameter, in a left gastrocnemius muscle with decreased intensity relative to that of normal muscle. After administration of gadolinium, the $T_{1}$ weighted image showed a well defined rim of contrast enhancement and a hypointense central area (A). An axial $T_{2}$ weighted image showed bright signal intensity in and around a focal mass-like lesion (B). 


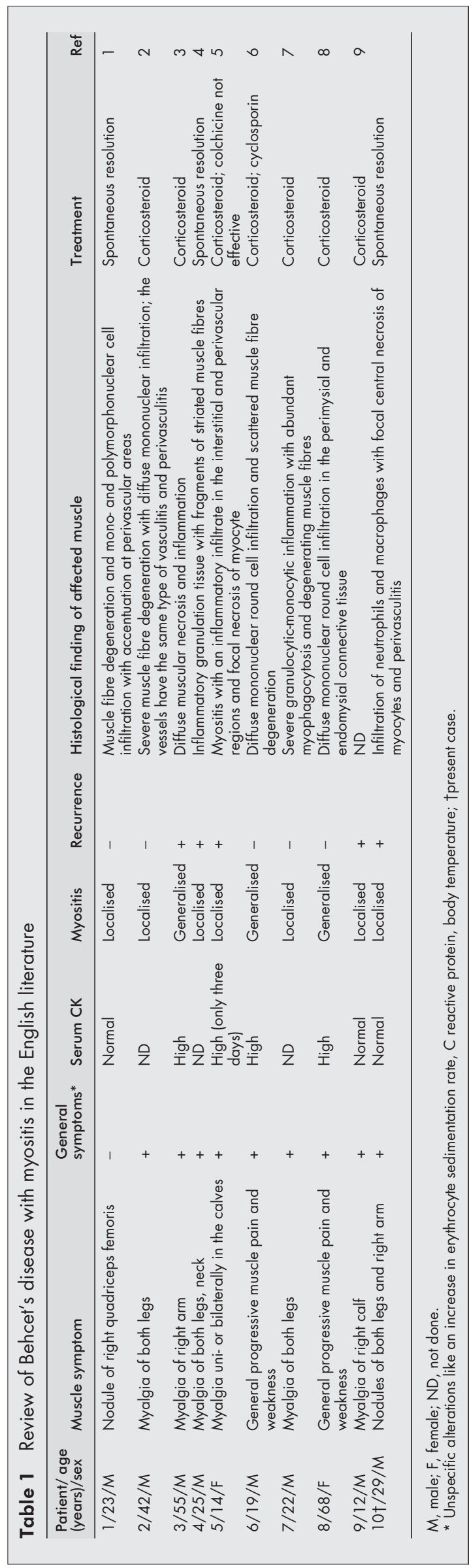

received colchicine during the acute phase of myositis, with no striking effect on the myositis. In our case, necrotising myositis did not recur after the administration of colchicine. The usefulness of colchicine for prevention of myositis in Behçet's disease needs to be further studied.

Authors' affiliations

H Sarui, T Maruyama, I lto, N Takeda, K Yasuda, Third Department of Internal Medicine, Gifu University School of Medicine, Japan N Yamakita, Department of Internal Medicine, Matsunami General Hospital, Japan

M Nose, Second Department of Pathology, Ehime University School of Medicine, Japan

Correspondence to: Dr H Sarui, Third Department of Internal Medicine, Gifu University School of Medicine, 40 Tsukasa-machi Gifu 500-8705 Japan; sarui@cc.gifu-u.ac.jp

Accepted 4 March 2002

\section{REFERENCES}

1 Yazici H, Tuzuner N, Tuzun Y, Yurdakul S. Localized myositis in Behçet's disease [letter]. Arthritis Rheum 1981;24:636.

2 Vincenzo DG, Giuseppe C, Fortunato M, Guido V. Myositis in Behçet's disease. Arthritis Rheum 1982;25:1025.

3 Arkin CR, Rothchild BM, Florendo NT, Popoff N. Behçet's syndrome with myositis: a case report with pathologic findings. Arthritis Rheum 1980:23:600-4

4 Finucane P, Doyle C, Ferriss J, Molloy M, Murnaghan D. Behçet's syndrome with myositis and glomerulonephritis. Br J Rheumatol $1985 ; 24: 372-5$.

5 Lang BA, Laxer RM, Thorner P, Greenberg M, Silverman ED. Pediatric onset of Behçet's' syndrome with myositis: case report and literature review illustrating unusual features. Arthritis Rheum 1990;33:418-25. 6 Lingenfelser T, Duerk H, Stevens A, Grossmann T, Knorr M, Saal JG. Generalized myositis in Behçet's disease: treatment with cyclosporine. Ann Intern Med 1992:116:651-3.

7 Worthmann F, Bruns J, Turker T, Gosztonyi G. Muscular involvement in Behçet's disease: case report and review of the literature. Neuromuscul Disord 1996;6:247-53.

8 Zen-niyoii M, Okamura S, Harada K, Igarashi S, Sunaga C, Oshimoto $\mathrm{H}$, et al. Intestinal Behcet's disease associated with generalized myositis. Gastrointest Endosc 2000:51:359-61.

9 Uziel Y, Lazarov A, Cordoba M, Wolach B. Paediatric Behcet's disease manifested as recurrent myositis: from an incomplete to a full-blown form. Eur J Pediatr 2000;159:507-8.

10 Yurdakul S, Mat C, Tuzun Y, Ozyazgan Y, Hamuryudan V, Uysal O, et al. A double-blind trial of colchicines in Behçet's syndrome. Arthritis Rheum 2001;44:2686-92. 


\title{
Systemic lupus erythematosus with haemophagocytosis and severe liver disorder
}

\author{
E Maeshima, T Kobayashi, M Mune, S Yukawa
}

Ann Rheum Dis 2002;61:753-754

W e report the case of a 30 year old woman who was diagnosed with systemic lupus erythematosus $(\mathrm{SLE})^{1}$ and had received prednisolone and cyclosporin A (CsA). In November 1999 a haematological examination showed a slight increase in transaminases. With no improvement in transaminase values, CsA was discontinued, and prednisolone was continued at $20 \mathrm{mg} /$ day. Because of general malaise, she was admitted in January 2000.

\section{CASE REPORT}

A haematological examination showed a marked decrease in white blood cells (WBC) to $1.4 \times 10^{9} / 1$, with a slight anaemia, but platelets were within the normal range. Aspartate aminotransferase (AST) and alanine aminotransferase (ALT) were considerably increased to $617 \mathrm{U} / \mathrm{l}$ (normal 13-33) and $350 \mathrm{U} / \mathrm{l}$ (normal 6-27), respectively. Ferritin was also increased to $2306 \mathrm{ng} / \mathrm{ml}$ (normal 5-178). C reactive protein (CRP) was increased to $7.9 \mathrm{mg} / \mathrm{l}$ (normal 0-4). Anti-double stranded DNA antibodies were increased to $297.8 \mathrm{IU} / \mathrm{ml}$ (normal 0-11.9). $\mathrm{CH}_{50} 17 \mathrm{U} / \mathrm{ml}$ (normal 30-50) showed severe hypocomplementaemia. Soluble interleukin 2 receptor (sIL2R) was high at 807 $\mathrm{U} / \mathrm{ml}$ (normal 145-519). Serum studies for hepatitis B virus, hepatitis $C$ virus, herpes simplex virus, and Epstein-Barr virus were negative. Direct immunoperoxidase staining using a monoclonal antibody (HRP-C7) measurement, a marker of cytomegalovirus (CMV) antigenaemia, was 1/34 000. This level is associated with asymptomatic CMV antigenaemia. ${ }^{23}$ Bone marrow aspiration and liver biopsy were performed. In the bone marrow, histiocytic haemophagocytosis was seen (fig lA). Liver biopsy showed moderate centrilobular large droplet fatty degeneration, hepatocytic rupture-induced lipogranuloma, and focal necrosis of hepatic cells (fig 1B). There was no lymphocyte invasion or intracytoplasmic inclusion bodies. Immunostaining was negative for CMV. Reactivated SLE associated with haemophagocytosis and a liver disorder was diagnosed. Gammaglobulin and ganciclovir were given for CMV antigenaemia. The CRP declined and CMV became negative, but fever continued. WBC decreased to $1.1 \times 10^{9} / 1$, and AST and ALT further increased to $1081 \mathrm{U} / 1$ and $591 \mathrm{U} / \mathrm{l}$, respectively, with a remarkable reduction in the $\mathrm{CH}_{50}$ to $9 \mathrm{U} / \mathrm{ml}$.

Betamethasone was given at $6 \mathrm{mg} /$ day, and CsA was resumed at $200 \mathrm{mg} /$ day. Subsequently, fever abated, and the WBC increased to $3.4 \times 10^{9} / 1$ and eventually reached normal. sIL2R fell to normal. Transaminases gradually improved, and she was discharged in April 2000. Finally, transaminases fell to the normal range in June 2000.

\section{DISCUSSION}

Possible causes of haemophagocytosis include viral infections in this patient, as well as SLE itself, because the disease was active. However, owing to the negative results of serum studies for several viruses, SLE itself was thought to be the cause of haemophagocytosis.

sIL2R, a marker of activated T cells, ${ }^{4}$ increases in active SLE or rises before activation of SLE. ${ }^{5-7}$ It is evident from these reports that activated $\mathrm{T}$ cells play an important part in the pathophysiology of active SLE. Both immune complex and hypocomplementaemia and also activated $\mathrm{T}$ cells played an
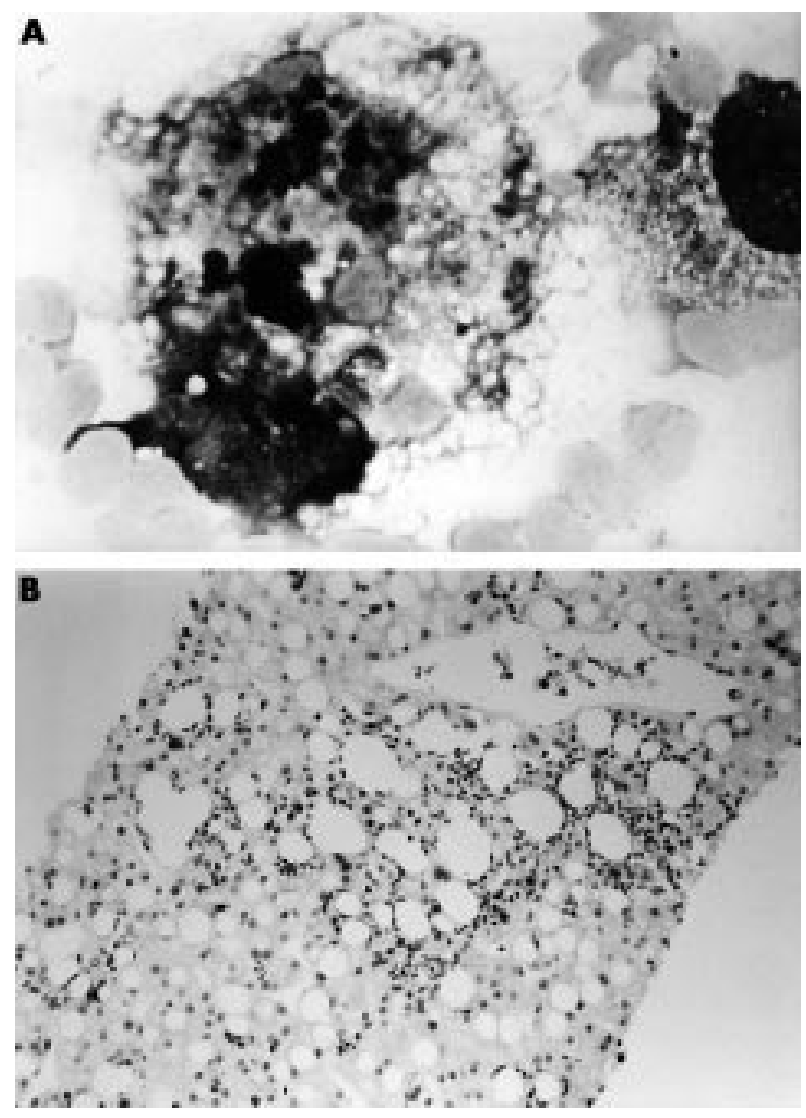

Figure 1 (A) Haemophagocytosis in bone marrow. The histiocyte showed phagocytosis of various haemopoietic cells including granulocytes, platelets, and erythrocytes. (May-Giemsa stain, original magnification $\times 1000$.) (B) The findings of hepatocytes rupture-induced lipogranuloma with focal necrosis of hepatic cells. (Haematoxylin-eosin stain, $\times 200$.)

important part in the mechanism of haemophagocytosis in our patient. CsA, which inhibits helper T cells, ${ }^{8}$ was effective, suggesting that cytokines also were important in the mechanism of haemophagocytosis.

In SLE, greatly increased transaminases are uncommon. In our patient, according to the definition and diagnostic criteria for CMV infection-induced hepatitis and cholangitis, ${ }^{9}$ CMV hepatitis was unlikely. Infections due to viruses other than CMV were also unlikely because no inclusion body was found. In addition, an examination of her liver did not point to a hepatic disorder induced by a thrombotic event. Steatosis found in SLE is generally accepted as a condition associated with drugs such as corticosteroids. ${ }^{10}$ However, hepatic disorder in our patient occurred as part of active SLE, and activated T lymphocytes and hypercytokinaemia played important roles as in the mechanism of haemophagocytosis, because sIL2R was high and improved as the clinical symptoms and liver transaminases improved with combined treatment with corticosteroids and CsA. 


\section{Authors' affiliations}

E Maeshima, T Kobayashi, M Mune, S Yukawa Third Department of Internal Medicine, Wakayama Medical College, 811-1 Kimiidera, Wakayama City, Wakayama 641-0012, Japan

Correspondence to: Dr E Maeshima; etsukoma@wakayama-med.ac.jp

Accepted 17 January 2002

\section{REFERENCES}

1 Tan EM, Cohen AS, Fries JF, Masi AT, Mcshane DJ, Rothfield NF, et al. The 1982 revised criteria for the classification of systemic lupus erythematosus. Arthritis Rheum 1982;25:1271-7.

2 Van den Berg AP, van der Bij W, van Son WJ, Anema J, van der Giessen M, Schirm J, et al. Cytomegalovirus antigenemia as a useful marker of symptomatic cytomegalovirus infection after renal transplantation-A report of 130 consecutive patients. Transplantation 1989;48:991-5

3 The TH, van der Ploeg $M$, van den Berg AP, Vlieger AM, van der Giessen $M$, van Son WJ. Direct detection of cytomegalovirus in peripheral blood leukocytes-a review of the antigenemia assay and polymerase chain reaction. Transplantation 1992;54:193-8.
4 Rubin LA, Kurman CC, Fritz ME, Biddinson WE, Boutin B, Yarchoan R, et al. Soluble interleukin 2 receptors are released from activated human lymphoid cells in vitro. J Immunol 1985;135:3172-7.

5 Semenzato G, Bambara LM, Biasi D, Frigo A, Vinante F, Zuppini B, et al. Increased serum levels of soluble interleukin-2 receptor in patients with systemic lupus erythematosus and rheumatoid arthritis. J Clin Immunol 1988;8:447-52

6 Tokano Y, Murashima A, Takasaki Y, Hashimoto H, Okumura K, Hirose $\mathrm{S}$. Relation between soluble interleukin 2 receptor and clinical findings in patients with systemic lupus erythematosus. Ann Rheum Dis 1989;48:803-9.

7 Raziuddin S, Al-Janadi MA, Al-Wabel AA. Soluble interleukin 2 receptor levels in serum and its relationship to T cell abnormality and clinical manifestations of the disease in patients with systemic lupus erythematosus. J Rheumatol 1991:18:831-6.

8 Ho S, Clipstone N, Timmermann L, Northrop J, Graef I, Fiorentino D, et al. The mechanism of action of cyclosporin A and FK 506. Clin Immunol Immunopathol 1996:80:S40-5.

9 Liungman P, Plotkin SA. Workshop on CMW disease; definitions, clinical severity scores, and new syndromes. Scand J Infect Dis Suppl 1995:99:87-9.

10 Van Hoek B. The spectrum of liver disease in systemic lupus erythematosus. Neth J Med 1996;48:244-53.

\title{
Ultrastructural study of the muscle coat of the gastric wall in a case of systemic sclerosis
}

\author{
L Ibba-Manneschi, A Del Rosso, S Pacini, A Tani, P Bechi, M Matucci Cerinic
}

Ann Rheum Dis 2002;61:754-756

t n systemic sclerosis (SSc), which affects the microcirculation and leads to fibrosis of skin and internal organs, ${ }^{1}$ the oesophagus and the colon are the gastrointestinal (GI) segments most commonly affected, even though other tracts can be impaired. ${ }^{23}$

In SSc, a few ultrastructural examinations of the oesophageal and rectal wall have been made, ${ }^{4}$ but no study has been carried out on the stomach. This prompted us to examine the gastric wall of a patient with SSc by transmission electron microscopy (TEM) in order to investigate the components of the muscle coat.

\section{CASE REPORT}

In 1997 a 52 year old woman, with limited SSc (ISSc) since 1979, came to our attention. She had Raynaud's phenomenon, sclerodactyly, anticentromere antibodies, and Sjögren's syndrome, but no lung, heart, and kidney disease. From the onset of her SSc, the patient had severe involvement of the distal oesophagus, which was confirmed by oesophagogastroscopy.

In May 1998 the gastro-oesophageal symptoms worsened despite treatment (ranitidine and, later, omeprazole and cisapride) and the patient underwent a Nissen-Rossetti laparoscopic fundoplication. Eight months later, as she became progressively unable to eat, she underwent a total gastrectomy with a Roux-en-Y oesophagojejunal anastomosis operation.

Samples of gastric anterior wall near the greater curvature, from the fundus, corpus, and antrum, were obtained, processed routinely for electron microscopy and, then, ultrathin sections were observed by TEM Jeol 1010.

At TEM, in the muscle coat of the fundus, corpus, and antrum, wide areas of marked focal fibrosis, characterised by collagen and elastic fibre depositions, were seen surrounding smooth muscle cells (smcs) and widening intercellular spaces (figs $1 \mathrm{~A}$ and B). This finding was in agreement both with the ultrastructural features of SSc of the $\operatorname{skin}^{6}$ and internal organs, ${ }^{7}$ and with the structural changes seen in the GI tract. ${ }^{3}$ The small number of fibroblasts found in the gastric muscle layers suggests that elastin and collagen fibres may be produced by smcs themselves, and not by fibroblasts, as shown in SSc skin. ${ }^{6}$ Indeed, considerable amounts of elastin were often found in invaginations of smc cell membrane. The fibrosis enveloping smcs might account for impaired cellular contraction and its propagation from cell to cell.

Several smcs were either contracted, with thickened dense bands (fig 1B), or stretched, with long and thin dense bands along the cell membrane (fig lA), indicating a different stage of smc contraction in the SSc stomach. These observations disagreed with the ultrastructural findings in SSc oesophagus, where only thickened dense bands were seen, while long and thin dense bands were noticed in patients with diffuse oesophageal spasm.

In smcs, cytoplasmic vacuolisation and swollen mitochondria (fig lA) were often found. Moreover, myofilaments and thickened dense bodies were severely disarrayed (fig 1B), indicating an ineffective filament contraction.

In myenteric plexus, large sized neurones showed well preserved Golgi apparatus, rough endoplasmic reticulum, some lipofuscin bodies, and diffuse slight cytoplasmic vacuolisation. Nerve bundles containing many axons were close to vessels and smcs.

The axoplasm of nerve fibres was pale, oedematous, and scarce in neurotubules and neurofilaments, with occasional swollen mitochondria and lipofuscin bodies (figs IC and E) as reported in nerve amyelinic bundles of SSc rectum wall. ${ }^{5}$

In SSc stomach, as seen in SSc oesophageal muscle coat, nerve endings close to smcs and vessels showed conserved morphology with intact synaptic vesicles containing electron dense granules (fig 1D). ${ }^{4}$ Often, abundant elastic and collagen fibres enveloped nerve endings, separating them from smcs (fig 1D). This finding, together with the alterations in the axoplasm cytoskeletal elements, may account for the impairment 

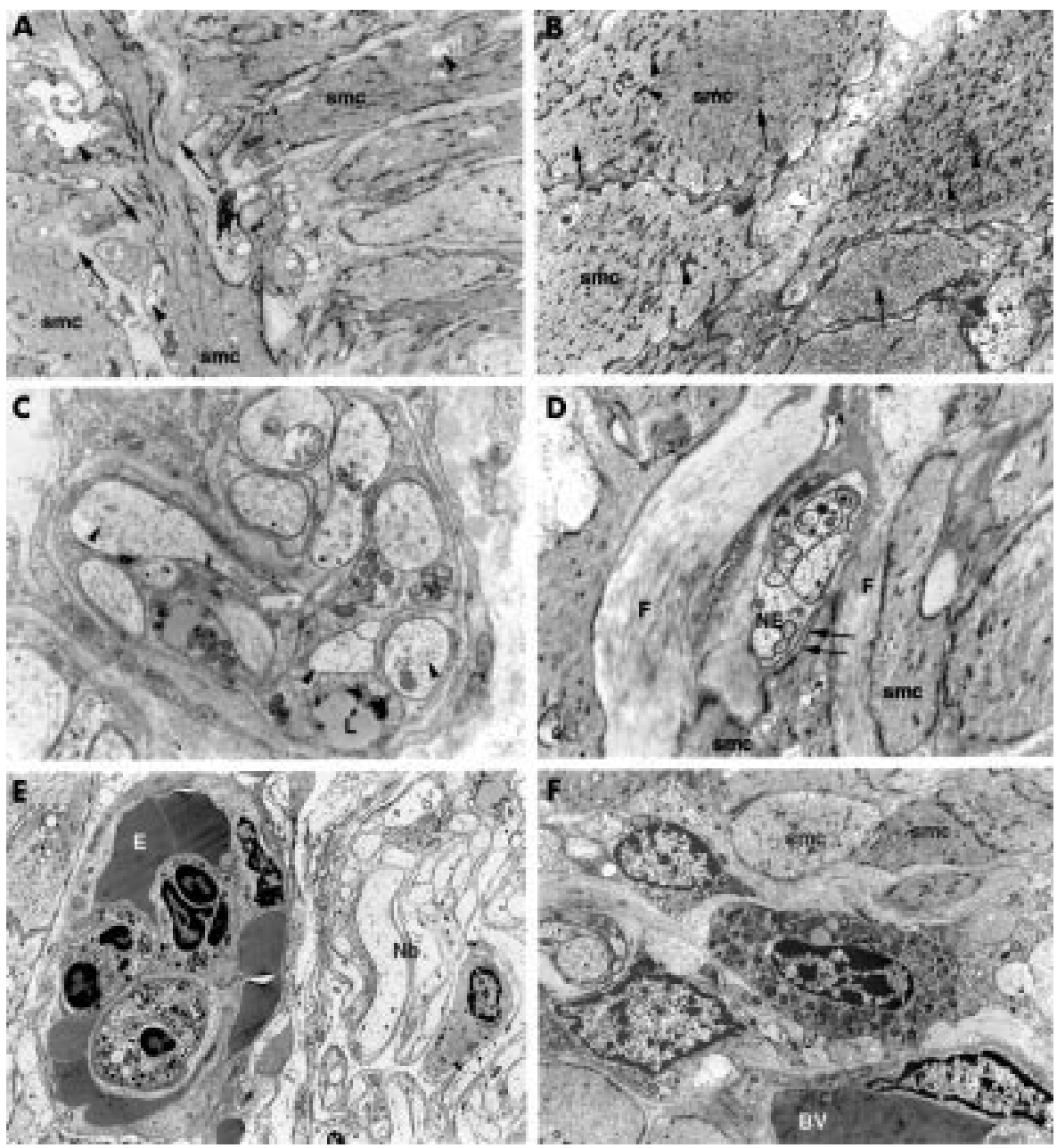

Figure 1 Stomach of a patient with ISSc-muscle coat. (A) Circular and longitudinal muscle layers. Note the marked fibrosis among the smooth muscle cells (smcs) (arrows). Sometimes smcs show a severe cytoplasmic vacuolisation (arrowheads); (B) a group of smcs. Myofilaments and dense bodies show a severe disarray (arrows). The dense bodies are thickened (arrowheads). F, collagen fibres; (C) nerve bundle containing many axons in myenteric plexus area. The axoplasm appears oedematous and poor in neurotubules and neurofilaments (arrowheads). L, lipofuscinic bodies; (D) nerve ending (NE), embedded in abundant collagen fibres (F) shows just one close contact area with an smc (arrows); (E) blood vessel, with lumen completely occluded by erythrocytes (E) and neutrophils (N) is close to a nerve bundle (Nb) containing many altered axons; (F) mast cell rich in granules is evident between a blood vessel (BV) and the smcs. Original magnification: (A) $\times 5000 ;(B, E, F) \times 3000 ;(C) \times 8000 ;(D) \times 6000$.

in axonal transport and in electric transmembrane transmission, respectively. These observations substantiate the alterations in nervous transmission that might be responsible for GI dismotility in advanced SSc.

Small vessels of the gastric muscle wall were lined by preserved endothelial cells, and the basement membrane was sometimes thickened or laminated, or both (fig IE). In SSc skin and rectum wall microvessels, on the contrary, swollen endothelial cells occluding the lumen, and thickened and laminated perivascular basal lamina, were seen. ${ }^{58}$

In the stomach wall, the microvascular lumen was partially or completely occluded by erythrocytes and neutrophils (fig $1 \mathrm{E})$, which contributed to tissue hypoperfusion and ischaemic damage. Neutrophils were also seen passing through the vascular wall into the interstitial space. Mast cells, rich in granules or partially degranulated, were present between vessels and smcs (fig lF).

\section{DISCUSSION}

As far as we know this is the first study reporting ultrastructural modifications in the gastric wall of a patient with ISSc. Severe alterations of smcs and nerve components, and prominent fibrosis are the main hallmarks in the stomach of a patient with longstanding ISSc, while the microvasculature is quite preserved.

Ultrastructural studies performed up to now did not clarify whether smc alterations are primary or secondary to neural and/or vascular involvement, in the genesis of GI changes in SSc. ${ }^{10}$ Therefore, further studies on the GI tract of patients in the early phase of SSc are warranted in order to understand and clarify the primary target of the disease and its progression.

\section{ACKNOWLEDGEMENT}

We are grateful to APAI (Associazione Patologie AutoImmuni) for continuous support.

\section{Authors' affiliations}

L lbba-Manneschi, S Pacini, A Tani, Department of Anatomy, Histology and Forensic Medicine, University of Florence, Florence, Italy A Del Rosso, M Matucci Cerinic, Department of Internal Medicine,

Rheumatology Section, University of Florence

P Bechi, Clinical Surgery, University of Florence

Correspondence to: Dr L Ibba-Manneschi, Department of Anatomy, Histology and Forensic Medicine, viale Morgagni 85, 50134, Florence, Italy; ibba@unifi.it

Accepted 4 February 2002 


\section{REFERENCES}

1 Clements PJ, Furst DE. Systemic sclerosis. Baltimore: Williams and Wilkins, 1995

2 Lock G, Holtstege A, Lang B, Schölmerich J. Gastrointestinal manifestation of progressive systemic sclerosis. Am J Gastroentero 1997;92:763-71.

3 Sjogren RW. Gastrointestinal motility disorders in scleroderma. Arthritis Rheum 1994;37:1265-82.

4 Russell ML, Friesen D, Henderson RD, Hanna WM. Ultrastructure of the esophagus in scleroderma. Arthritis Rheum 1982;25:1 $117-22$.

5 Malandrini A, Selvi E, Villanova M, Sabatini L, Salvadori C, Gambelli

$S$, et al.Autonomic nervous system and smooth muscle cell involvement in systemic sclerosis: ultrastructural study of three cases. J Rheumatol 2000;27:1203-6.
6 Perlish JS, Lemlich G, Fleishmeyer R. Identification of collagen fibrils in scleroderma skin. J Invest Dermatol 1988;90:48-54.

7 Harrison NK, Myers AR, Corrin B, Soosay G, Dewar A, Black CM, et al. Structural features of interstitial lung disease in systemic sclerosis. Am Rev Respir Dis 1991;144:706-13.

8 von Bierbrauer A, Barth P, Willert J, Mennel HD, Schmidt JA. Electron microscopy and capillaroscopically guided nailfold biopsy in connective tissue diseases: detection of ultrastructural changes of the microcirculatory vessels. Br J Rheumatol 1998:37:1272-8.

9 Matucci Cerinic M, Generini S, Pignone A, Casale R. The nervous system in systemic sclerosis (scleroderma). Rheum Dis Clin North Am 1996:22:879-91.

10 Lock G, Straub RH, Zeuner M, Antoniou E, Holstege A, Schölmerich J, et al.Association of autonomic nervous dysfunction and esophageal dysmotility in systemic sclerosis. J Rheumatol 1998;25:1330-5. Letters

\title{
Relapse of rheumatoid arthritis after substitution of oral for parenteral administration of methotrexate
}

\author{
A Rozin, D Schapira, A Balbir-Gurman, Y Braun-Moscovici, D Markovits, D Militianu, \\ M A Nahir
}

W read with interest the letters: "Is parenteral methotrexate worth trying?" by Osman and

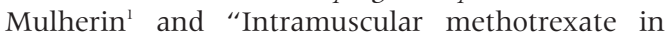
inflammatory rheumatic disease" by Burbage, Gupta, and Lim. $^{2}$ We would like to present our findings, which indicate that parenteral methotrexate (MTX) may be more efficient than oral MTX at the same dose and in the same patients with inflammatory joint disease.

During the second half of 2000 we were faced with an unexpected shortage of parenteral MTX (ABIC, Israel) which lasted for more than five months, and patients were switched to oral MTX (Lederle, Germany). This gave us the opportunity to evaluate the difference in efficacy of parenteral versus oral administration of low dose MTX.

\section{CASE REPORTS}

Eight patients (seven female) with a mean age of 55 (38-70) years, who fulfilled the following criteria, were analysed retrospectively: (a) all had inflammatory joint diseases (four seropositive rheumatoid arthritis (RA), two seronegative RA (revised American Rheumatism Association criteria for RA), and two RA-like psoriatic arthropathy); $(b)$ all were receiving parenteral MTX and were in complete clinical remission (fulfilling at least five of six criteria for complete clinical remission in RA); (c) all had an exacerbation of their disease when switched from parenteral to oral MTX at the same weekly dose and without any interval between the two treatments.

Ninety seven patients with inflammatory joint diseases were treated with parenteral MTX. Eighty one of them were faced with the drug supply shortage. Four patients remained in clinical remission for five months without MTX treatment. Eighteen who were not advised to switch immediately had an exacerbation of their disease within three weeks. The other 59 patients were switched to oral MTX without any treatment interval. Ten of the 59 patients received an oral dose more than 2.5-5 mg higher than the parenteral dose; no exacerbation occurred. Forty nine patients were switched to the same oral dose. Eight of them (16\%) deteriorated and became the subject of our investigation.
The following variables were investigated: duration of the disease and of the remission period, $x$ ray imaging (joint erosions), concurrent treatment, MTX weekly dose, EULAR disease activity score (DAS28 with three variables ${ }^{3}$ ) at the time of relapse and two months after renewing the parenteral MTX treatment, compared with remission period.

Table 1 summarises the patients' details. These patients did not differ from the patients who did not have an exacerbation after switching. All eight patients were in stable remission which had lasted for three years on average. Relapse occurred quite rapidly: 3-10 (mean 6) weeks after switching. The mean (SD) DAS28 activity index rose from 1.8 (0.4) to 4.9 (0.4).Within two months after reinstitution of the previous parenteral MTX marked improvement was noted from DAS28 $4.9(0.4)$ to DAS28 $3.4(0.6)$.

\section{DISCUSSION}

After oral administration MTX is rapidly but incompletely absorbed. Its bioavailability is about $70 \%$ at low doses $(\leqslant 10$ $\left.\mathrm{mg} / \mathrm{m}^{2}\right)$, approximately $15-20 \%$ lower than that of intramuscular (IM) or intravenous (IV) MTX. ${ }^{45}$ In addition, there is a marked interindividual and a moderate intraindividual variability in the extent of absorption of oral MTX. ${ }^{6}$ Oral administration in doses above $25 \mathrm{mg} /$ day is associated with lower bioavailability due to the saturation of the absorption mechanism. Thus in high doses the parenteral administration is mandatory. ${ }^{7}$ IM MTX showed higher bioavailability than oral MTX either as tablets or as solution. ${ }^{8}$ However, other studies have shown a similar MTX concentration after oral, IM, or IV administration. ${ }^{5}$

To compare the relative bioavailability of oral versus intramuscular administration in patients with RA, the pharmacokinetics of MTX at both the usual starting dose of $7.5 \mathrm{mg}$ and at established higher maintenance doses was examined in 21 patients. ${ }^{10}$ Pharmacokinetics measurements were repeated six and 18 months after baseline while patients were receiving maintenance doses of MTX (17.0 (3.8) $\mathrm{mg}$ ). The relative bioavailability of the maintenance dose was reduced by $13.5 \%$ as compared with the initial dose of $7.5 \mathrm{mg}$. The area under the curve of the serum concentration versus time curve 


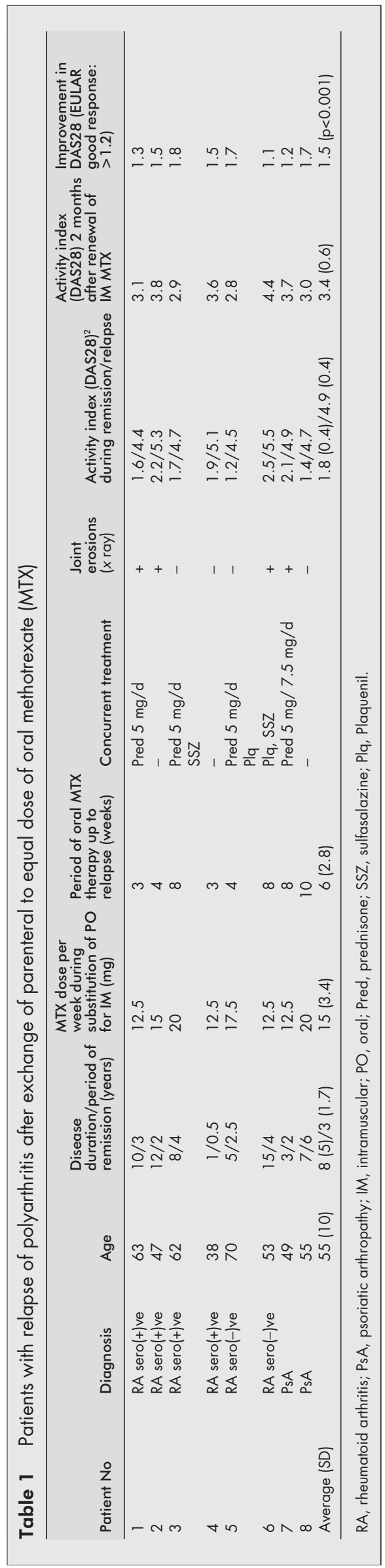

was significantly lower for oral than for IM administration at usual maintenance doses, but similar at an MTX dose of 7.5 mg a week. The authors concluded that clinicians using MTX should not assume constant and complete bioavailability across the dose range. The findings explained the benefit which follows the switching from oral to parenteral administration in patients receiving maintenance doses of MTX as well as the failure of the inverse switching reported here. It should be mentioned that all our patients were treated with MTX in doses higher than $7.5 \mathrm{mg} /$ week and from the study of Hamilton and Kremer $^{10}$ it seems that it is only safe to switch from IM to oral administration at a dose of $7.5 \mathrm{mg} /$ week. Two other recent studies also supported a switch to parenteral MTX in patients previously intolerant of, or who have failed to respond to, oral MTX. ${ }^{12}$

Various drugs currently used in RA may interact with MTX. It is known that corticosteroids do not interfere with the pharmacokinetics of MTX, whereas chloroquine may reduce gastrointestinal absorption of the drug. This might be relevant to two of our patients (Nos 5 and 6, table 1).

In conclusion, polyarthritis may be exacerbated owing to switching from parenteral to oral MTX using the same dosage. Reinstitution of IM MTX usually suppresses the disease activity.

\section{Authors' affiliations}

A Rozin, D Schapira, A Balbir-Gurman, Y Braun-Moscovici, D Markovits, M A Nahir, B Shine Department of Rheumatology, Rambam Medical Centre and Faculty of Medicine, Technion-Israel Institute of Technology, Haifa, Israel

D Militianu, Department of Medical Imaging, Rambam Medical Centre and Faculty of Medicine

Correspondence to: Dr A Rozin, Department of Rheumatology, Rambam, Medical Centre, PO Box 9602, Haifa 31096, Israel;

nahir@rambam.health.gov.i

Accepted 4 February 2002

\section{REFERENCES}

1 Osman A, Mulherin D. Is parenteral methotrexate worth trying? Ann Rheum Dis $2001 ; 60: 432$.

2 Burbage G, Gupta R, K. Lim. Intramuscular methotrexate in inflammatory rheumatic disease. Ann Rheum Dis 2001;60:1156

3 Van Gestel AM, Prevoo MLL, van 't Hof MA, van Rijswijk MH, van de Putte LB, van Riel PL. Development and validation of the European League Against Rheumatism response criteria for rheumatoid arthritis. Arthritis Rheum 1996;39:34-40.

4 Furst DE. Practical clinical pharmacology and drug interactions of low-dose methotrexate therapy in rheumatoid arthritis. Br J Rheumatol 1995;34(suppl 2):20-5.

5 Bannwarth B, Pehourcq F, Lequen L. Pharmacokinetics of methotrexate in rheumatoid arthritis: therapeutic implications. Therapie 1997;52:129-32

6 Lebbe C, Beyeler C, Gerber NJ, Reuchen J. Intraindividual variability of the bioavailability of low dose methotrexate after oral administration in rheumatoid arthritis. Ann Rheum Dis 1994;53:475-7.

7 Balis FM, Mirro JJ, Reaman GH, Evans WE, McCulty C, Doherty KM, et al. Pharmacokinetics of subcutaneous methotrexate. J Clin Oncol 1988;6: 1882-6.

8 Jundt JW, Browne BA, Fiocco GP, Steele AD, Mock D. A comparison of low dose methotrexate bioavailability: oral solution, oral tablet, subcutaneous and intramuscular dosing. J Rheumatol 1993;20:1845-9.

9 Seideman P, Beck O, Eksborg S, Wennberg M. The pharmacokinetics of methotrexate and its 7-hydroxy metabolite in patients with rheumatoid arthritis. Br J Clin Pharmacol 1993;35:409-12.

10 Hamilton RA, Kremer JM. Why intramuscular methotrexate may be more efficacious than oral dosing in patients with rheumatoid arthritis. $\mathrm{Br} J$ Rheumatol 1997;36:86-90. Letters 


\title{
Spontaneous spondylodiscitis caused by Klebsiella oxytoca
}

\author{
J M Sabio, M López-Gómez, J Jiménez-Alonso
}

Ann Rheum Dis 2002;61:758-759

S pontaneous infectious spondylodiscitis (SIS) is an uncommon cause of low back pain in adults ${ }^{1}$ being most commonly described in children. Most cases in adults follow spinal treatment, and adult cases unrelated to previous spinal surgical procedures are considerably less common. In contrast with postoperative patients, in whom the most common infecting organisms isolated were Staphylococcus aureus and Staphylococcus epidermidis, a wide variety of infectious agents have been implicated in SIS, including Klebsiella species. ${ }^{1-5}$ Klebsiella oxytoca is a non-motile, Gram negative bacillus, that can be differentiated from Klebsiella pneumoniae by its inability to produce indole from tryptophan. ${ }^{6}$ As far as we know, this is the first case of SIS caused by Koxytoca to be reported.

\section{CASE REPORT}

A 51 year old man with an antecedent of intravenous heroin addiction and two months' history of progressive thoracolumbar pain without fever was referred for investigation. Physical examination showed mild tenderness to palpation over D12-Ll and a painful paravertebral musculature contraction that limited movements of the back. Motor examination and deep tendon reflexes were normal. Several skin ulcers and venepuncture lesions in arms, hands, and legs were seen. The remainder of the examination was otherwise unremarkable.

Laboratory findings showed an erythrocyte sedimentation rate of $62 \mathrm{~mm} / \mathrm{lst} \mathrm{h}$; C reactive protein $83 \mathrm{mg} / \mathrm{l}$, fibrinogen 7.6 $\mathrm{g} / \mathrm{l}$, and a white blood cell count of $11.6 \times 10^{9} / 1$ with $78 \%$ polymorphonucleocytes. A chest radiograph and the remainder of the routine blood and urine determinations were normal. A Mantoux intradermor reaction test (2 UI PPD-RT23) was positive ( $15 \mathrm{~mm}$ in diameter). Serological tests for Brucella and HIV infection were negative and repeat sputum, blood, and urine cultures for bacteria and mycobacterium were also negative. Likewise, a skin ulcer specimen was examined and polymicrobial flora were isolated. A roentgenographic study of the lumbar spine showed degenerative changes and osteoporotic vertebral fractures in D12 and Ll, and narrowing of the disc space at D12-L1. Magnetic resonance imaging (MRI) confirmed narrowing of the disc space at D12-Ll, with end plate destruction of D12 and Ll (fig 1). Finally, a fine needle biopsy of the disc guided by computed tomography was performed and the specimen culture was positive for Koxytoca. In accordance with the antibiogram results, the patient received intramuscular ceftriaxone ( $2 \mathrm{~g} /$ day for six weeks). Two months later the patient had completely recovered and MRI showed significant improvement of the vertebral lesion.

\section{DISCUSSION}

Klebsiella species are an important cause of nosocomial and community acquired infection. Most of the Klebsiella strains implicated in invasive infections are K pneumoniae and $<13 \%$ of episodes of bacteraemia by Klebsiella were due to $K$ oxytoca. ${ }^{7-9}$ This micro-organism has been associated with urinary, respiratory, biliary tract, skin, and intravascular device infections. ${ }^{10}$ Although unusual, some cases of spondylodiscitis

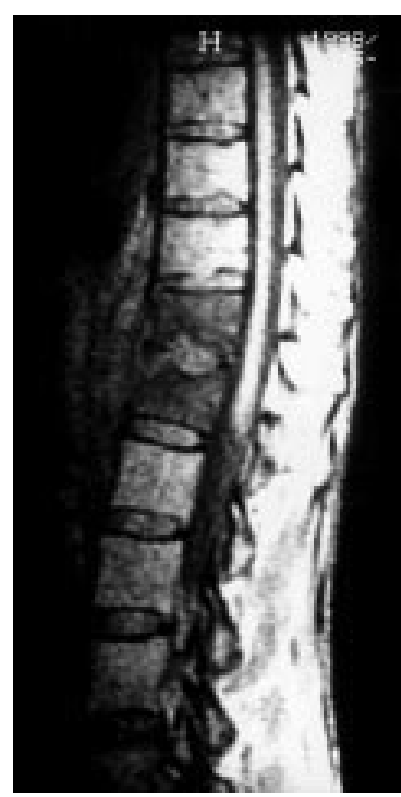

Figure 1 MRI showing the narrowness of the disc space at D12-L1, with end plate destruction of D12 and L1.

caused by K pneumoniae have been reported. ${ }^{1-5}$ However, as far as we know this is the first reported case of SIS due to $K$ oxytoca.

The clinical presentation of this patient was similar to that reported in other cases of SIS, irrespective of the causative organism. ${ }^{1}$ Schoferman et al pointed out that the infectious agents which play a part in SIS may be of relatively low virulence, ${ }^{11}$ causing an insidious onset and a subacute clinical course. This is in contrast with primary vertebral osteomyelitis, in which patients present a more acute course with obvious infection. In our case, blood cultures were negative. Honan et al found that 10/16 patients with spontaneous discitis also had negative blood cultures, ${ }^{1}$ underlining this possibly low virulence, although it might also be explained by the fact that discitis is delayed with respect to the bacteraemia. Likewise, it is remarkable that in the series of Lin et al, pyogenic metastatic foci were not found in any of the 43 patients with Koxytoca bacteraemia. ${ }^{10}$ These issues suggest that $K$ oxytoca may also have only a small ability to cause septic emboli and perhaps for this reason septic complications due to Koxytoca (such as SIS) are unusual.

Lin et al found that the most common underlying diseases associated with $K$ oxytoca bacteraemia were hepatobiliary diseases, neoplastic diseases, and diabetes mellitus. ${ }^{10}$ Other predisposing factors were prior antimicrobial treatment, urinary catheterisation or manipulation, corticosteroid treatment, recent surgery, and respiratory assistance. In our patient, none of these situations were present. He had only an active intravenous heroin addiction, and was negative for HIV infection when the spondylodiscitis developed. Many authors have concluded that immunological dysfunction has a relatively minor role in the pathogenesis of infection in injection drug users, compared with the repeated parenteral introduction of non-sterile material. ${ }^{12}$ Nevertheless, some immunological disorders have been reported, such as a depression of 
the blastogenic response of peripheral blood mononuclear cells to pokeweed mitogen and a depression of phagocytosis, superoxide production, and bactericidal activity of polymorphonuclear cells from intravenous heroin users. ${ }^{13}$ In these patients, osteomyelitis infection is usually due to $S$ aureus and $P$ aeruginosa, and the skin and the oral cavity are the most common point of entry. $K$ oxytoca is an unusual microorganism present in the skin, dregs being its principal source. Contamination by objects used for intravenous heroin introduction may be a possible cause of the Koxytoca infection in this case. Likewise, skin ulcers are extremely common in intravenous drug users. Although $S$ aureus and $\beta$-haemolytic streptococci remain the most common isolates, other Gram negative bacilli such as Klebsiella have an important role. Our patient had skin ulcers and these may be other possible points of entry for $K$ oxytoca, but in our case this micro-organism could not be isolated.

\section{Authors' affiliations \\ J M Sabio, M López-Gómez, J Jiménez-Alonso, Service of Internal Medicine, Virgen de las Nieves University Hospital, Granada, Spain}

Correspondence to: Dr J Jiménez-Alonso, Virgen de las Nieves University Hospital, Avda Fuerzas Armadas 12, 18012 Granada, Spain: jualso@hvn.sas.cica.es

Accepted 25 February 2002

\section{REFERENCES}

1 Honan $M$, White GW, Eisenberg GM. Spontaneous infectious discitis in adults. Am J Med 1996:100:85-9.
2 Kouroussis C, Georgoulias V, Souglakos J, Simvoulakis E, Karabekios $\mathrm{S}$, Samonis G. Spontaneous spondylodiscitis caused by Klebsiella pneumoniae. Infection 1999;27:368-9.

3 Sugawa M, Tanaka R, Nakamura M, Isaka N, Nishimura J, Kimura M, et al. A case of infectious pseudoaneurysm of the abdominal aorta associated with infectious spondylodiscitis due to Klebsiella pneumoniae. Jpn J Med 1989;28:402-5.

4 Porras JA, Bayona C, Gutiérrez MC, Vidal F. Vertebral osteomyelitis due to Klebsiella pneumoniae. An Med Interna 1994;1 1:154-5.

5 Gómez-Rodríguez N, Rey R, Ferreiro JL, Ibáñez-Ruán J, Sevillano J. Septic spondylodiscitis and epidural abcess by Klebsiella pneumoniae. An Med Interna 2000;17:311-13

6 Maslow JN, Brecher SM, Adams KS, Durbin A, Loring S, Arbeit RD. Relationship between indole production and differentiation of Klebsiella species: indole-positive and negative isolates of Klebsiella to be clonal source. J Clin Microbiol 1993:31:2000-3.

7 Watanakunakorn C, Jura J. Klebsiella bacteremia: a review of 196 episodes during a decade (1980-1989). Scand J Infect Dis $1991 ; 23: 399-405$

8 Yinnon AM, Butnaru A, Raveh D, Jerassy Z, Rudensky B. Klebsiella bacteremia: community versus nosocomial infection. QMM 1996;89:933-41.

9 Lee KH, Hui KP, Lim TK. Klebsiella bacteremia: a report of 101 cases from National University Hospital, Singapore. J Hosp Infect 1994;27:299-305

10 Lin RD, Hsueh PR, Chang SC, Chen YC, Hsieh WC, Luh KT. Bacteremia due to Klebsiella oxytoca: clinical features of patients and antimicrobial susceptibilities of the isolates. Clin Infect Dis 1997;24:1217-22.

11 Schofferman L, Schofferman J, Zucherman J, Gunthorpe H, Hsu K, Picetti $G$, et al. Occult infections causing persistent low-back pain. Spine 1989; 14:417-19

12 Peterson PK, Sharp B, Gekker G, Brummitt C, Keane WF. Opioid-mediated suppression of interferon-gamma production by cultured peripheral blood mononuclear cells. J Clin Invest 1987;80:824-31.

13 Tubaro E, Borelli G, Croce C, Cavallo G, Santiangeli C. Effect of morphine on resistance to infection. J Infect Dis 1983;148:656-66.

\section{Elderly onset isolated B27 associated dactylitis}

\section{A Padula, V Giasi, I Olivieri}

D actylitis, or "sausage-like" digit, is a typical manifestation of spondyloarthropathy $(\mathrm{SpA}) .^{1-6}$ Although more common in psoriatic arthritis, ${ }^{6}$ dactylitis has been seen in all forms of $\mathrm{SpA}$, including the undifferentiated forms (uSpA). ${ }^{1-6}$ In these latter cases, dactylitis usually occurs in association with the other clinical and radiological manifestations of SpA. ${ }^{2}$ However, occasionally, dactylitis may for a long time be the only clinical manifestation of the B27 associated disease process. ${ }^{78}$ This has been described in young and middle aged adults ${ }^{7}$ and in children. ${ }^{8}$ Recently, we observed the cases of two B27 positive subjects with elderly onset, isolated, longstanding dactylitis, which we report briefly here.

\section{CASE REPORTS}

The first patient, a 71 year old woman, was referred to us for evaluation of severe swelling and pain of the fourth finger of the right hand of nine months' duration. Her family history was negative for SpA and other B27 associated diseases. Her medical history was unremarkable, except for hypertension. The patient denied ever having had other clinical manifestations of SpA. Physical examination disclosed a marked swelling affecting the entire digit. The flexor synovial sheaths were so swollen and tender that the patient could not flex the finger. There was no pain and swelling at the fourth metacarpophalangeal and proximal and distal interphalangeal joints. The only abnormal laboratory measure was a $\mathrm{C}$ reactive protein of $30 \mathrm{mg} / \mathrm{l}($ normal <5). HLA typing showed A3, B27, and B53. Pelvis radiographs showed normal sacroiliac joints. The dactylitis was treated with steroid injections in the flexor synovial sheaths, with good results.

The second patient, a 62 year old man, had had "sausage-like digit" of the second right toe for three months when he was referred to us. His sister and aunt, examined in the previous 12 months in our department, were found to have B27 positive arthritis associated with ulcerative colitis and B27 positive elderly onset uSpA, respectively. The patient's medical history was unremarkable and did not disclose any other manifestation of the B27 associated disease process. Physical examination showed severe dactylitis with swelling and tenderness along the flexor synovial sheaths of the second right toe. The joints of the digit were not affected. Laboratory evaluation showed an erythrocyte sedimentation rate of $30 \mathrm{~mm} / \mathrm{lst} \mathrm{h}$ and a $\mathrm{C}$ reactive protein of $30 \mathrm{mg} / \mathrm{l}$. HLA typing showed A2, B27, and B45. Pelvis radiographs were normal. Dactylitis was successfully treated with steroid injections into the flexor synovial sheaths.

\section{DISCUSSION}

Our two elderly patients were unquestionably affected by B27 positive, late onset uSpA. They were B27 positive, had no history of previous manifestations of SpA, and developed an isolated severe dactylitis. In both cases clinical examination showed marked swelling and tenderness along the flexor tendon sheaths and normal metacarpophalangeal and interphalangeal joints. Recent studies with magnetic resonance 
imaging and ultrasound have shown that the lesion always present in dactylitis is flexor tendon tenosynovitis and that arthritis of the adjacent joints may be absent. ${ }^{34910}$ In addition, our studies on dactylitis have demonstrated that physical examination has a high specificity and sensitivity in diagnosing dactylitis and that, therefore, imaging techniques are not essential in routine practice. ${ }^{34}$

uSpA include forms of SpA that fail to meet criteria for the definite forms. ${ }^{15}$ Recent epidemiological studies using the Amor and/or the ESSG criteria for all forms of SpA have shown that uSpA is more common or as common as ankylosing spondylitis. ${ }^{11}{ }^{12}$ The clinical spectrum of uSpA is wide, resulting from the various combinations of clinical and radiological manifestations. These include peripheral arthritis, peripheral enthesitis, dactylitis, inflammatory spinal pain, buttock pain, sacroiliitis, chest wall pain, acute anterior uveitis, aortic insufficiency together with conduction disturbances, each of which may also occur in isolation. ${ }^{2}$ In 1977 De Ceular et al described the cases of young and middle aged B27 subjects with isolated dactylitis. ${ }^{7}$ In 1988 Siegel and Baum reported the same situation in B27 positive children. ${ }^{8}$

In the past few years attention has been drawn to late onset uSpA. In 1995 we reported on 23 patients with uSpA who had the first symptom after the age of 45 years. $^{2}$ Of these, 12 had three or more manifestations of SpA, seven showed two manifestations, and four only one. Of these four, two had peripheral enthesitis and two acute anterior uveitis. The present report expands the clinical spectrum of late onset SpA with the inclusion of isolated dactylitis.

\section{Authors' affiliations}

A Padula, V Giasi, I Olivieri, Rheumatology Department of Lucania San Carlo Hospital of Potenza and Madonna delle Grazie Hospital of Matera, Potenza and Matera, Italy
Correspondence to: Dr I Olivieri, Rheumatology Department of Lucania, Ospedale S Carlo, Contrada Macchia Romana, 85100 Potenza, Italy; ignazioolivieri@tiscalinet.it

Accepted 22 February 2002

\section{REFERENCES}

1 Khan MA, van der Linden SM. A wider spectrum of spondyloarthropathies. Semin Arthritis Rheum 1990;20:107-13.

2 Olivieri I, Padula A, Pierro A, Favaro L, Oranges GS, Ferri S. Late onse undifferentiated seronegative spondyloarthropathy. J Rheumatol 1995;22:899-903.

3 Olivieri I, Barozzi L, Favaro L, Pierro A, De Matteis M, Borghi C, et al. Dactylitis in patients with seronegative spondylarthropathy: assessment by ultrasonography and magnetic resonance imaging. Arthritis Rheum 1996:39:1524-8.

4 Olivieri I, Barozzi L, Pierro A, De Matteis M, Padula A, Pavlica P. Toe dactylitis in patients with spondyloarthropathy: assessment by magnetic resonance imaging. J Rheumatol 1997;24:926-30.

5 Zeidler H, Maw W, Khan MA. Undifferentiated spondyloarthropathies. Rheum Dis Clin North Am 1992;18:187-202.

6 Salvarani C, Cantini F, Olivieri I, Macchioni P, Niccoli L, Padula A, ef al. Isolated peripheral enthesitis and/or dactylitis: a subset of psoriatic arthritis. J Rheumatol 1997;24:1106-10.

7 De Ceular K, van der Linden JMP, Cats A. "Sausage-like" toes (dactylitis) and HLA B27. J Rheumatol 1977;4 (suppl 3):66-9.

8 Siegel DM, Baum J. HLA-B27 associated dactylitis in children. J Rheumatol 1988; 15:976-7.

9 Kane D, Greaney T, Bresnihan B, Gibney R, Fitzgerald O. Ultrasonography in the diagnosis and management of psoriatic dactylitis. I Rheumatol 1999;26:1746-51

10 Wakefield RJ, Emery P, Veale D. Ultrasonography and psoriatic arthritis [letter]. Kane D, FitzGerald O [reply]. J Rheumatol 2000;27:1564-5.

11 Boyer GS, Templin DW, Cornoni-Huntley JC, Everett DF, Lawrence RC, Heyse SF, et al. Prevalence of spondyloarthropathy in Alaskan Eskimos. J Rheumatol 1994;21:2292-7.

12 Braun J, Bollow M, Remlinger G, Eggens U, Rudwaleit M, Distler A, Sieper J. Prevalence of spondylarthropathies in HLA-B27 positive and negative blood donors. Arthritis Rheum 1998;41:58-67.

\title{
Poor predictive value of antinucleosome and antineutrophil cytoplasmic antibodies in a 270 inception cohort of patients with early naked arthritis of less than one year's duration
}

\author{
J-M Berthelot, A Saraux, M Audrain, P Le Goff, M Hamidou, J-Y Muller, P Youinou
}

l n most studies examining the outcome of early arthritis, lupus and vasculitides are rare events, occurring in only $1-3 \%$ of cases. ${ }^{1}$ However, they should be diagnosed as quickly as possible. Thus, it might be worth testing patients with early arthritis for the presence of anticytoplasmic neutrophil antibodies (ANCA). ${ }^{2}$ Indeed, a strong positivity for ANCA might suggest that vasculitides, including Wegener's disease and microscopic polyangiitis, were probably present before the onset of the clinical features typical of these disorders. ${ }^{34}$ Similarly, and in addition to looking for antinuclear antibodies (and/or anti-dsDNA antibodies), it has been claimed that testing for antinucleosome antibodies might be a valuable additional test for the early detection of lupus; this last subset of autoantibodies has shown good sensitivity (56\%) and excellent specificity (97\%) for longlasting systemic lupus erythematosus (SLE). ${ }^{5}$ However, these as- sumptions have not yet been supported by data from an inception cohort of patients with early unclassified arthritis tested by routine methods.

We tested for ANCA by indirect immunofluorescence (IIF) ( $1: 20$ dilution) and for antinucleosome-IgG by a commercial enzyme linked immunosorbent assay (ELISA) kit (BMD DNA-NUC-LISA) in the baseline sera of 270 patients with early onset arthritis without clinical signs suggestive of visceral disease. We then followed up these patients for a mean (SD) of 28.5 (12.1) months.

For the ANCA testing, although 23/270 (9\%) baseline sera were positive, neither of the two patients later diagnosed as having vasculitides were positive by IIF-ANCA. Moreover, for both patients, even testing for anti-proteinase 3 (anti-PR3) and anti-myeloperoxidase (anti-MPO) by ELISA was negative at baseline. 
For antinucleosome testing, at the 10 IU threshold suggested by the manufacturer, 109/270 (40\%) sera were positive, including 51/114 (45\%) rheumatoid arthritis (RA) and $20 / 34$ (59\%) spondyloarthropathy ( SpA). However at the 20 IU threshold only $4 \%$ were still positive, including $2 / 33(6 \%)$ unclassified arthritis, 5/105 (5\%) RA, 2/52 (4\%) SpA, 1/5 (20\%) sicca syndrome, and only $1 / 5(20 \%)$ patients later diagnosed as having SLE. Moreover for this single patient, the diagnosis was already firmly established, especially as the antinuclear antibody titre was $1 / 1000$ and anti-dsDNA were positive. Hence the positive predictive value for SLE of antinucleosome testing was $1 / 11$, and the sensitivity $1 / 5$.

These low sensitivities do not support the working hypothesis that systematic screening for IIF-ANCA and antinucleosome antibodies is useful for the diagnosis of vasculitides in early arthritis and of SLE in patients with "naked" arthritis. Such results were somewhat expected, given that systemic vasculitis or SLE with arthritis as precursor are quite uncommon events. However, they confirm that determination of ANCA and antinucleosome antibodies should not be carried out in the absence of clinical extra-articular manifestations, especially as low ANCA titres have already been demonstrated in a large percentage of more benign conditions like early RA and early SpA. ${ }^{6-9}$ We would therefore quite agree with the conclusion of Merkel et al, that instead of systematic screening for ANCA by IIF, only those patients with features atypical for RA, SpA, or undifferentiated arthritis should be tested for ANCA, using an ELISA for anti-PR3 and anti-MPO together with IIF-ANCA. ${ }^{9}$

Likewise in our cohort, antinucleosome antibodies were positive at low values at baseline in several conditions other than SLE and in only 1/5 patients with SLE. There are few reports on antinucleosome antibodies and SLE, and thus definite conclusions cannot be reached about the overall additional value of this test to support the diagnosis of SLE. ${ }^{10}$ However, our results strongly suggest that systematic testing for antinucleosome antibodies should not be a substitute for a careful search for all visceral signs suggestive of lupus in a patient presenting with seemingly "naked" arthritis.

\section{ACKNOWLEDGEMENT}

Funding was provided by the Centre Hospitalier de Nantes and the Programme Hospitalier de Recherche Clinique 1995.

\section{Authors' affiliations}

J-M Berthelot, Rheumatology Unit, Nantes University Hospital, 44093, $\mathrm{CHU}$, Nantes, France

A Saraux, P Le Goff, Rheumatology Unit, Brest University Hospital, 29629, CHU, Brest, France

M Audrain, J-Y Muller, Laboratory of Immunology, Nantes University Hospital, 44093, CHU, Nantes, France

M Hamidou, Internal Medicine Unit, Nantes University Hospital, 44093, $\mathrm{CHU}$, Nantes, France

P Youinou, Laboratory of Immunology, Brest University Hospital, 29629, $\mathrm{CHU}$, Brest, France

Correspondence to: Dr J-M Berthelot, Rheumatology Unit, CHU Nantes, Hôtel-Dieu, 44093, Nantes-Cedex 01, France;

jeanmarie.berthelot@chu-nantes.fr

Accepted 4 February 2002

\section{REFERENCES}

1 Berthelot JM, Saraux A, Maugars Y, Prost A, Le Goff P. The taxonomy-nosology of arthritis: the experience of early-arthritis clinic. Semin Arthritis Rheum 2001:30:354-65.

2 Soubrier M, Le Seaux S, Dubost JJ, Mizony MH, Ristori JM, Bussière JL. Polyarthrite, manifestation inaugurale $\mathrm{d}^{\prime}$ une polyangéite microscopique. A propos de deux observations. Rev Med Interne 2000;21:78-82.

3 Choi HK, Liu S, Merkel PA, Colditz GA, Niles JL. Diagnostic performance of antineutrophil cytoplasmic antibody tests for idiopathic vasculitides: metaanalysis with a focus on antimyeloperoxidase antibodies. J Rheumatol 2001;28:1584-90.

4 Wiik A. Anti-neutrophil cytoplasmic antibodies tests: which tests should be used in practice? Intern Med 2001:40:466-70.

5 Bruns A, Blass S, Hausdorf G, Burmester GR, Hiepe F. Nucleosomes are major $T$ and $B$ cell autoantigens in systemic lupus erythematosus. Arthritis Rheum 2000;43:2307-15.

6 De Bandt M, Meyer O, Haim T, Kahn MF. Antineutrophil cytoplasmic antibodies in rheumatoid arthritis patients. $\mathrm{Br} J$ Rheumatol 1996;35:38-43

7 Vittecoq O, Jouen-Beades F, Krzanowska K, Bichon-Tauvel JF, Menard $\mathrm{JF}$, Daragon A, et al. Prospective evaluation of the frequency of clinical significance of antineutrophil cytoplasmic and anticardiolipin antibodies in community cases of patients with rheumatoid arthritis. Rheumatology (Oxford) 2000;39:481-9.

8 Locht H, Skogh T, Kihlstrom E. Anti-lactoferrin antibodies and other type of anti-neutrophil cytoplasmic antibodies (ANCA) in reactive arthritis and ankylosing spondylitis. Clin Exp Immunol 1999; 1 17:568-73.

9 Merkel PA, Polisson RP, Chang Y, Skates SJ, Niles JL. Prevalence of antineutrophil cytoplasmic antibodies in a large inception cohort of patients with connective tissue disease. Ann Intern Med 1997; 126:866-73

10 Amoura Z, Koutouzov S, Chabre H, Cacoub P, Amoura I, Musset L, et al. Presence of antinucleosome autoantibodies in a restricted set of connective tissue diseases. Arthritis Rheum 2000;43:76-84

\title{
Cogan's syndrome with antineutrophil cytoplasmic autoantibody
}

\author{
M lkeda, H Okazaki, S Minota
}

Ann Rheum Dis 2002;61:761-762

C ogan's syndrome is a rare disease characterised by nonsyphilitic interstitial keratitis with vestibuloauditory dysfunction, including loss of hearing, tinnitus, and vertigo. ${ }^{1}$ We report here a case of Cogan's syndrome positive for antineutrophil cytoplasmic antibody (ANCA). This case is interesting in consideration of the pathogenesis of this syndrome.

\section{CASE REPORT}

In May 1999 a 61 year old man was admitted to our hospital with fever and myalgia localised to the lower part of both legs.
He had a history of lung tuberculosis at 22 years old, chronic sinusitis at 30, and bilateral otitis media at 53. On admission, laboratory tests showed a white blood cell count of $11.2 \times 10^{9} / 1$ and a CRP level of $63 \mathrm{mg} / \mathrm{l}$. Serum levels of creatine kinase, alanine aminotransferase, and aspartate aminotransferase, and a urinary examination were normal. A serological test was positive for perinuclear ANCA (pANCA) and myeloperoxidase ANCA (MPO-ANCA; $105 \mathrm{EU} / \mathrm{ml}$ (normal <10 EU/ml)), but negative for syphilis and cytoplasmic ANCA (cANCA). Electromyographic findings were normal. Although the pathological change of vasculitis was not detected in the biopsied muscle, the presence of microscopic polyangiitis was 
highly suspected based on the high titre of MPO-ANCA. Prednisolone (30 mg/day) was given at once, and after one month the levels of $C$ reactive protein (CRP) and MPO-ANCA decreased to $5 \mathrm{mg} / \mathrm{l}$ and $12 \mathrm{EU} / \mathrm{ml}$, respectively, with clinical improvement.

While receiving continuous prednisolone treatment, in August 2000, the patient suddenly developed severe frontotemporal headache and vertigo. The CRP level increased to 43 $\mathrm{mg} / \mathrm{l}$. Two weeks later, complete hearing loss of his left ear developed. Immediate administration of betamethasone ( 10 $\mathrm{mg}$ /day) for three days did not improve his hearing.

In January 2001 myalgia and weight loss developed and continued, and the levels of CRP and MPO-ANCA were raised at $68 \mathrm{mg} / \mathrm{l}$ and $46 \mathrm{EU} / \mathrm{ml}$, respectively. In February 2001 redness of both eyes due to keratouveitis suddenly occurred, which improved after treatment with corticosteroid eye drops. Cyclophosphamide ( $50 \mathrm{mg} /$ day) was also given together with betamethasone (1.5 mg/day), and complete clinical and serological remission was obtained (CRP $5 \mathrm{mg} / \mathrm{l}$, MPO-ANCA 10 $\mathrm{EU} / \mathrm{ml}$ ). A diagnosis of Cogan's syndrome was made based upon the clinical constellation of keratouveitis, sensorineural hearing loss, and suspected systemic vasculitis.

\section{DISCUSSION}

Previously, Cheson et al reviewed 53 cases of Cogan's syndrome ; 10/18 vessel or muscle biopsy specimens showed inflammatory vascular changes, of which four were considered to be diagnostic of polyarteritis in large and medium sized arteries. ANCA is widely used as a useful diagnostic marker for small vessel vasculitis, including Wegener's granulomatosis, microscopic polyangiitis, pauci-immune necrotising crescentic glomerulonephritis, and Churg-Strauss syndrome, although this test is occasionally positive in various other conditions. Recently, it has been reported that the combination of immunoassays for anti-MPO and indirect immunofluorescence for pANCA is highly specific for the diagnosis of systemic vasculitis. ${ }^{3}$ Until now, five cases of Cogan's syndrome associated with ANCA have been reported, including ours, ${ }^{4-7}$ and two of them also showed ANCA related glomerulonephritis. In our case, pANCA and MPO-ANCA were positive, and audiovestibular abnormalities and keratouveitis were present, but other manifestations of systemic vasculitis were not noted. We speculate, therefore, that all sizes of arteries may be affected in Cogan's syndrome.

The cause of Cogan's syndrome is still unknown. Interestingly, upper respiratory tract infections have been reported to precede the onset of Cogan's syndrome in $40 \%$ of cases, ${ }^{8}$ suggesting that one of the triggering factors may be upper respiratory infection. Our patient also had a history of upper respiratory infections. The research group in the National Institute of Health found that patients with Cogan's syndrome had significantly high titres of antibodies to Chlamydia trachomatis. Ljungstrom et al reported a patient with Cogan's syndrome who had a fourfold increase in serum IgG antibody titre to Chlamydia pneumoniae. ${ }^{10}$ Furthermore, it has been reported that Chlamydia infections are related to vascular injury, such as arteriosclerosis and vasculitis. A relationship between previous Chlamydia infection and coronary artery disease is supported by seroepidemiological studies. It is suggested that the bacteria adhere to endothelial cells, because Chlamydia pneumoniae is detected in atherosclerotic plaques by both polymerase chain reaction and culture. In our case, the IgG titre to Chlamydia pneumoniae was negative, but the IgA titre was positive (2.23, cut off point 0.9 ). We suggest that the IgG titre might have been negative in our case because the titre was measured several months after treatment with corticosteroid and cyclophosphamide.

This case suggests a possibility that antinuclear antibodies are related to the pathogenesis of Cogan's syndrome, although further studies are required to confirm this hypothesis.

\section{Authors' affiliations}

M Ikeda, Health Science Centre, Utsunomiya University, Tochigi, Japan H Okazaki, S Minota, Division of Rheumatology and Clinical Immunology, Jichi Medical School, Tochigi, Japan

Correspondence to: Dr M lkeda, Health Science Centre, Utsunomiya University, Utsunomiya City, Tochigi 321-8505, Japan;

ikedam@cc.utsunomiya-u.ac.jp

Accepted 7 January 2002

M Hamidou, Internal Medicine Unit, Nantes University Hospital, 44093, $\mathrm{CHU}$, Nantes, France

P Youinou, Laboratory of Immunology, Brest University Hospital, 29629, $\mathrm{CHU}$, Brest, France

Correspondence to: Dr J-M Berthelot, Rheumatology Unit, CHU Nantes, Hôtel-Dieu, 44093, Nantes-Cedex 01, France;

jeanmarie.berthelot@chu-nantes.fr

Accepted 4 February 2002

\section{REFERENCES}

1 Cogan DS. Syndrome of nonsyphilic interstitial keratitis and vestibuloauditory symptoms. Arch Ophthalmol 1945;33:144-9.

2 Cheson BD, Bluming AZ, Alroy J. Cogan's syndrome: systemic vasculitis. Am J Med 1976; 60:549-55.

3 Choi HK, Liu S, Merkel PA, Colditz GA, Niles JL. Diagnostic performance of antineutrophil cytoplasmic antibody tests for idiopathic vasculitis: metaanalysis with a focus on antimyeloperoxidase antibodies. J Rheumatol 2001;28:1584-90.

4 Yamanishi Y, Ishioka S, Takeda M, Maeda H, Yamakido M. Atypical Cogan's syndrome associated with antineutrophil cytoplasmic autoantibodies. Br J Rheumatol 1996;35:601-3.

5 Cohen Tervaert JW, Mulder L, Stegeman C, Elema J, Huitema M, The $\mathrm{H}$, et al. Occurrence of autoantibodies to human leukocyte elastase in Wegener's granulomatosis and other inflammatory disorders. Ann Rheum Dis 1993;52:115-20.

6 Suzuki M, Arimura Y, Minoshima S, Fukuoka K, Miyake N, Ishizuka S, et al. A case of myeloperoxidase-specific antineutrophil cytoplasmic antibody (MPO-ANCA)-related glomerulonephritis associated with Cogan's syndrome. Jpn J Nephrol 1996;38:423-7.

7 Brijker F, Magee CC, Tervaert JW, O'Neill S, Walshe JJ. Outcome analysis of patients with vasculitis associated with antineutrophil cytoplasmic antibodies. Clin Nephrol 1999;52:344-51.

8 Vollertsen RS, McDonald TJ, Younge BR, Banks PM, Stanson AW, Ilstrup DM. Cogan's syndrome: 18 cases and a review of the literature. Mayo Clin Proc 1986;61:344-61

9 Haynes BF, Kasier-Kupfer MI, Mason P, Fauci AS. Cogan syndrome: studies in thirteen patients, long-term follow-up, and a review of the literature. Medicine (Baltimore) 1980;59:426-41.

10 Liungstrom L, Franzen C, Schlaug M, Elowson S, Viidas U. Reinfection with Chlamydia pneumoniae may induce isolated and systemic vasculitis in small and large vessels. Scand J Infect Dis 1997;104\{suppl):37-40. 


\section{Haemochromatosis arthropathy and repetitive trauma}

\section{Morgan, D Smith}

\section{CASE REPORT}

A 51 year old factory worker presented with a two year history of pain and swelling of the right index and middle finger metacarpophalangeal (MCP) joints. He had no significant past medical history and there was no family history of arthritis. Examination showed bony deformity and diminished range of movement at the right index and middle MCP joints. The left hand and other joints were normal. There were no abnormalities on examination of his cardiovascular system or abdomen.

His job in a car assembly factory for the previous 10 years had involved lifting mesh car components from a container using only his right hand, and he estimated that he would carry out this manoeuvre about 4000 times in a day.

Radiographs of his right hand showed joint space narrowing and osteophytes at the right second and third MCPs (fig 1A). The left hand was radiologically normal (fig lB).

His rheumatoid factor, blood count, and erythrocyte sedimentation rate were negative/normal. Serum alkaline phosphatase was $150 \mathrm{U} / \mathrm{l}$ (normal 30-130). Fasting glucose was $5.8 \mathrm{mmol} / \mathrm{l}$. Serum ferritin was $1184 \mathrm{ng} / \mathrm{ml}$ (normal 20-350) with a serum iron of $42 \mu \mathrm{mol} / \mathrm{l}$ (normal 14-31) and transferrin saturation $80 \%$ (normal 20-30). Genetic studies showed him to be homozygous for the Cys282 Tyr mutation, the genotype found in over $90 \%$ of patients with haemochromatosis in the UK. He was diagnosed with haemochromatosis and treated by venesection.

His family members have been screened for the condition. One son aged 29 years has been found to have a transferrin saturation of $60 \%$. Ferritin level is normal. Genetic testing has been carried out and shown him to be a compound heterozygote with Cys282 Tyr and His 63 Asp mutations, a genotype associated with haemochromatosis in $20 \%$ of cases. He is at present being kept under surveillance.
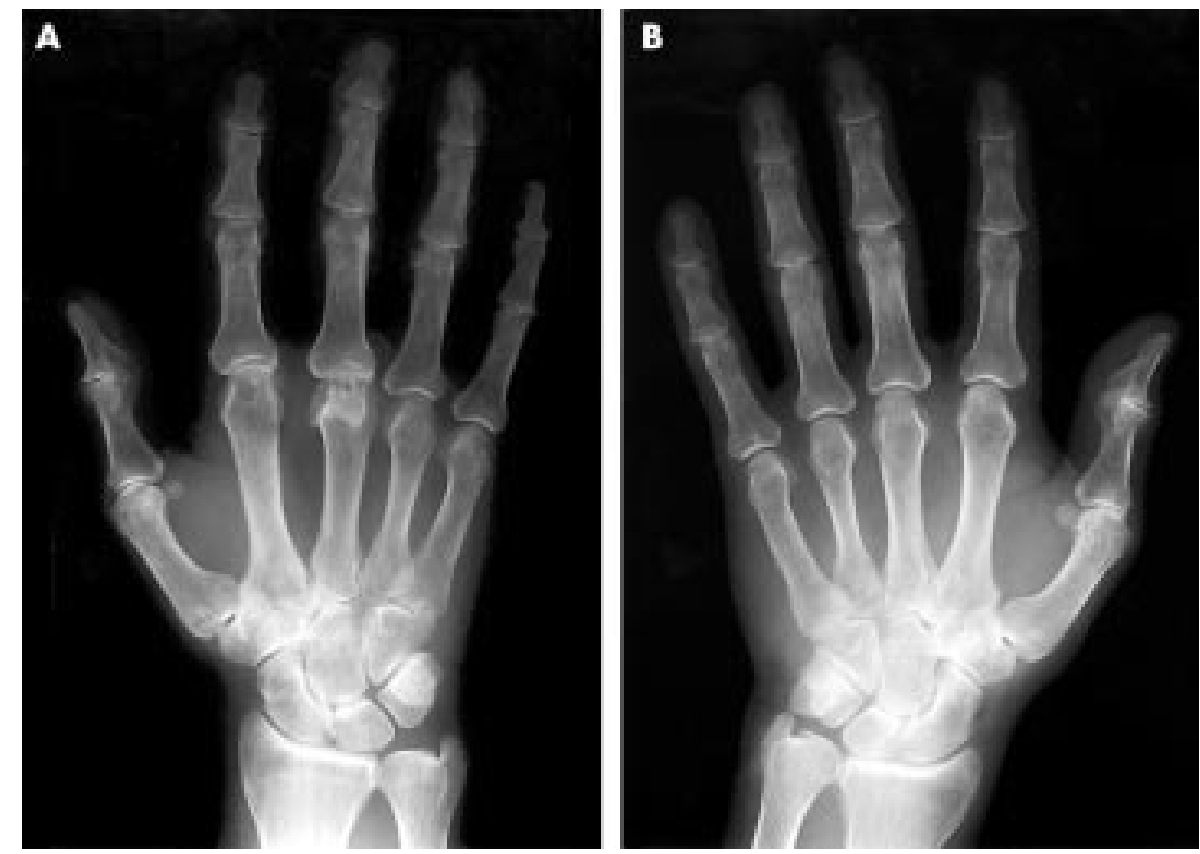

Figure 1 (A) Radiograph of the right hand with joint space narrowing and osteophytes at the right second and third MCP joints;

(B) radiograph of the left hand showing a normal appearance.
Ann Rheum Dis 2002;61:763

\section{DISCUSSION}

There have been reported cases of undiagnosed haemochromatosis presenting as exercise related joint pains in recreational runners with underlying haemochromatosis arthropathy. ${ }^{1}$ However, this patient's unilateral arthritis suggests that minor trauma may interact with genetic haemochromatosis to determine the distribution of joint damage. This is consistent with the observation of Lee et al, who described unilateral arthropathy on the normal side of a patient with haemochromatosis and a hemiparesis. ${ }^{2}$

Whether the course of arthritis is altered by venesection is unclear. However, it is important to make an early diagnosis of haemochromatosis in a patient presenting with arthropathy because venesection may prevent internal organ damage.

\section{Authors' affiliations}

C Morgan, General Medicine, Morriston Hospital, Swansea, UK D Smith, Rheumatology Department, Morriston Hospital, Swansea, UK

Correspondence to: Dr C Morgan, 95 Romilly Crescent, Pontcanna, Cardiff CF1 1 9NQ, UK; carysmorgan@hotmail.com

Accepted 5 February 2002

\section{REFERENCES}

1 McCurdie I, Perry JD. Haemochromatosis and exercise related joint pains. BM 1999;318:449-51.

2 Lee JC, Salonen DC, Inman RD. Unilateral haemochromatosis arthropathy on a neurogenic basis. J. Rheumatol 1997;24:2476-8. 